\title{
Technology Evaluation: Fitting Tools and Techniques to the Stages of the Evaluation Process
}

\author{
F. Romero ${ }^{1}$, F. Barbosa ${ }^{1}$ \\ ${ }^{1}$ Department of Production and Systems Engineering, University of Minho, Guimarães, Portugal \\ (fromero@dps.uminho.pt)
}

\begin{abstract}
In this work we propose to look at the process of evaluation and selection of technologies. Building on evaluation models that assume stages and decision moments, we propose a complement to those models by suggesting specific methodologies, tools and criteria that seem to be appropriate for each specific stage. The research was based on a structured inquiry on the evaluation practices of thirty three firms from different sectors. One of the main results was the realization that the criteria, tools and methodologies that are adopted by firms are not uniform throughout the process of evaluation and adoption of the technologies. It depends on the stage of the process. Accordingly, we propose a division of the process in specified stages and we identify which criteria, tools and methodologies firms' values most at each one*.
\end{abstract}

Keywords - Technology evaluation, evaluation models, evaluation stages, evaluation techniques and criteria

\section{INTRODUCTION}

Research on the process of evaluation and selection of technologies has suggested many approaches. However, many models seem to be based on financial analysis, and many of the suggested models seem to rely on a relatively narrow set of methodologies and criteria. In this research, there was an effort to identify whether this perspective is effectively followed by firms. The literature is not conclusive on this matter. Apparently, the models used by firms in their evaluation processes differ according to the type of technology that is under scrutiny. For instance, the evaluation of manufacturing technologies or information technologies seems indeed to be essentially based on financial models [1], but portfolio evaluation includes market, technological, strategic and economic criteria. Many firms do not apply any rigorous or systematic methodology, due to the absence of knowledge on evaluation methodologies, or difficulties or high costs in assessing them [2]. Systematic processes, which assume several steps and decision moments during the course of evaluation, seem to conduct firms to higher performances [3]. In this research, and building on the literature, the evaluation process is also assumed to be divided in stages. However, and adding to the literature, there is an identification, for each stage, of specific techniques, methodologies and criteria. The stages assume a decrease in the perception of the uncertainty associated with technology. Thus, the methodologies employed are more

\footnotetext{
* This research was funded by FCT-Fundação para a Ciência e Tecnologia, under the project "PEst-OE/EME/UI0252/2011"
}

qualitative and subjective in the first stages and become progressively more quantitative and objective. The paper aims to present a more integrated perspective on the issue, backed by relevant empirical data. The main research questions are: what are the main tools, methodologies, criteria, and relative weights with which firm evaluate their investment in new technologies? Which tools, methodologies, criteria are used in each stage of the evaluation process?

\section{CONCEPTUAL FRAMEWORK}

As a result of competitive challenges and the rapid growth of scientific knowledge, companies are urged to seek new ways of implementing and acquiring technology [4]. Technology evaluation is a fundamental aspect in the process of decision making, and this term is often used in the literature, in a way that leads to confusion and imprecision, to identify the whole process of evaluation, selection and adoption [5]. This importance is reflected in the interest shown by many researchers in this area, who have already identified many methodologies and critical aspects of this process [6]. Most approaches suggest that most evaluation methods used are essentially quantitative and derive from traditional financial evaluation techniques such as NPV $[7,8,9]$, Payback Period $[9,10$, 11], ROI [1, 11], DCF [11, 12, 13], among others. However, the evaluation of new ideas and business concepts is a challenge for companies, especially in its early stages of development where there is not a tangible commercial product [14]. Traditional financial techniques do not include non-quantitative factors (intangibles, both in terms of benefits, or in terms of costs or risks) that may have great importance in terms of evaluation and adoption [15]. This makes it difficult to establish an objective system for evaluating intangible results, since it is not possible to design and apply appropriate quantitative indicators [16]. Small firms say that a major barrier to implementation of an innovative idea is the lack of an appropriate valuation technique and, very often, they are guided by intuition and experience [17]. Thus, it assumes significant importance the establishment of appropriate metrics for evaluating investments in new technologies [18], according to the nature of the technology and its level of maturity. The evaluation process allows us to formulate an opinion about what are the best options for technology investment. However, because of trade offs and anticipation of the consequences of decisions, this optimizing perspective is not always feasible [19]. 


\section{METHODOLOGY}

The data on which this study relies consists of primary data collected from the Portuguese business sector. The research was based on a quantitative approach and on an intentional non-probabilistic sampling strategy. Data was obtained through an online quantitative structured questionnaire sent to 200 firms. Some interviews with selected firms were also realized, in order to substantiate or consolidate some of the data that was obtained. The extent and depth of the questionnaire limited the number of responses. We received thirty three answers (a response rate of $16.5 \%$ ) and the sample includes micro, small, medium and large firms. A proportion of the sample includes conglomerates, and in fact, the sample represents approximately one hundred and twenty two firms. The sample is composed of five microenterprises, six small companies, twelve medium companies and ten large companies. Although it is a non-probabilistic sample, its scope and creditworthiness is important, since, according to official R\&D statistics, it represents $22.34 \%$ of total Portuguese investment in business R\&D [20].

\section{TECHNOLOGY EVALUATION}

In this section the analysis of the results highlight some important factors that have not been properly addressed in the literature. We assume that the process of technology evaluation and selection is divided in stages, similarly to the main literature on the subject, but, unlike this one, we find that the techniques, tools and decision criteria associated with each stage is different, and it varies accordingly.

As mentioned in the review section above, most approaches assume that the most widely used methods are quantitative and derive from traditional financial evaluation techniques. Our results do not support that view. Although quantitative techniques are used, they are used only in some stages of the process, as a determinant decision tool.

We identified five stages in the evaluation process, which are: the idea generation stage (a stage where several ideas are generated but not formally evaluated), the screening stage (a stage involving a preliminary assessment of the most promising ideas generated in the previous stage), the idea evaluation stage (a stage involving the collection of hard data on the selected ideas coming from previous the stage), the feasibility stage (a stage involving the consolidation of the idea concept and the evaluation of functional, operational and financial aspects) and the opportunity stage (a stage involving thorough financial and project evaluation). In the following tables, we present the tools and methodologies used in the first three stages, and then a table presenting the differential evaluation criteria that firms attribute to each stage, supporting our argument that tools, methodologies and criteria are not indiscriminately used throughout the evaluation and selection process.
TABLE I

\section{TOOLS AND TECHNIQUES USED IN THE STAGE OF} IDEA GENERATION

\begin{tabular}{lc}
\hline Type of tools and techniques & $\begin{array}{c}\text { Mean } \\
(\mathrm{n}=33)\end{array}$ \\
\hline Meetings & 3,67 \\
Brainstorming & 3,64 \\
Check Lists & 3,03 \\
Flowcharts & 2,94 \\
Questionnaires & 2,79 \\
String diagram & 1,64 \\
Idefo diagram & 1,61 \\
Lotus flower & 1,61 \\
Edgar & 1,55 \\
Jb help me & 1,52 \\
\hline Likert scale: $1=$ Never, $2=$ Rarely,3=Usually; \\
$4=$ Very frequently;5=Always.
\end{tabular}

As mentioned before, only the five most valued and the five least valued factors are indicated in the tables. For each table and question there were many more factors that were asked to the respondents.

Table I presents the results of the questionnaire regarding the tools and techniques used in the stage of idea generation.

The main tools and techniques used by firms in the stage of idea generation are the meetings. Another main tool and technique is brainstorming. Checklists are also widely used tools in this stage. The results regarding the evaluation methods used in the next stage, the screening stage, are quite different from those used in the previous stage, and the results are shown in Table II.

TABLE II

\begin{tabular}{|c|c|}
\hline Evaluation methods & $\begin{array}{c}\text { Mean } \\
(\mathrm{n}=33)\end{array}$ \\
\hline Experience & 4,09 \\
\hline $\begin{array}{l}\text { Opinion and advice from companies } \\
\text { and collaborative networks }\end{array}$ & 3,03 \\
\hline Intuition & 2,85 \\
\hline Check lists & 2,79 \\
\hline Others & 2,00 \\
\hline Rapidscreen & 1,76 \\
\hline Strategy Canvas & 1,58 \\
\hline COAP & 1,45 \\
\hline Quick Outlook commercialization Assessment & 1,39 \\
\hline TEC Algorithm & 1,30 \\
\hline
\end{tabular}


TABLE III

EVALUATION METHODS USED IN THE

IDEA EVALUATION STAGE

\begin{tabular}{lc}
\hline Evaluation methods & $\begin{array}{c}\text { Mean } \\
(\mathrm{n}=33)\end{array}$ \\
\hline Experience & 3,97 \\
Competitive advantage & 3,88 \\
Business goals & 3,88 \\
Cost benefit analysis & 3,88 \\
Strategic Analysis Model & 3,61 \\
Delphi & 1,48 \\
Stochastic programming & 1,39 \\
Fuzzy logics & 1,36 \\
Stochastic differential equation & 1,36 \\
TEC Algorithm & 1,36 \\
\hline Likert scale: $1=$ Never, 2=Rarely, 3=Usually; \\
4=Very frequently; $5=$ Always
\end{tabular}

The main evaluation methods used in the screening stage are the experience, opinion and advice from companies and collaborative networks, and intuition. The least used are methodologies that are quite systematic and that involve a considerable amount of quantitative considerations. The degree of subjectivity involved in this stage is somewhat surprising, and it is not very often referred to in the literature, since at this stage it would be expected that the collection and analysis of some hard numbers would have a greater weight in terms of decision making. In fact, the importance of quantitative methods will only become visible in the next stage, and particularly, in the last stages of the evaluation process. Table III presents the results regarding the evaluation methods used in the idea evaluation stage.

The main evaluation methods used in the idea evaluation stage are experience, competitive advantage and business goals. Curiously, subjective criteria (experience) still seems to dominates the picture, although more structured and quantitative methods acquire a substantial weight. Notice that the methods and the tools that are used in this stage are also quite different from those used in the previous stages, reflecting the different decision criteria that are used in the different stages. The decision criteria become gradually less subjective and more quantitative. The next section highlights this "evolution" in the process of decision making of firms, and it will include the final stages of the process.

\section{WEIGHING THE DIFFERENT DIMENSIONS AND CRITERIA USED IN THE EVALUATION PROCESS ACCORDING TO THE SPECIFIC STAGE OF DEVELOPMENT}

During the above presentation, discussion and analysis of the results, it became clear the validity of the assumption that evaluation and selection methodologies, tools and criteria are not uniform along the evaluation process.

TABLE IV

WEIGHTING OF THE DIFFERENT DIMENSIONS AND CRITERIA USED IN THE EVALUATION PROCESS

\begin{tabular}{|c|c|c|c|c|}
\hline \multirow[t]{2}{*}{ Dimension } & \multicolumn{4}{|c|}{ Stage } \\
\hline & $\begin{array}{l}\text { Screening } \\
\text { stage }\end{array}$ & $\begin{array}{c}\text { Idea } \\
\text { evaluation } \\
\text { stage }\end{array}$ & $\begin{array}{l}\text { Feasibility } \\
\text { stage }\end{array}$ & $\begin{array}{l}\text { Opportunity } \\
\text { Stage }\end{array}$ \\
\hline Market & $44,94 \%$ & $27,91 \%$ & $19,30 \%$ & \\
\hline Technology & $38,20 \%$ & $23,10 \%$ & & \\
\hline Subjectivity & $16,86 \%$ & $9,06 \%$ & & \\
\hline Product/Service & & $21,22 \%$ & & \\
\hline Risk & & $18,71 \%$ & $12,21 \%$ & \\
\hline Economic/Financial & & & $20,43 \%$ & \\
\hline Technical & & & $16,20 \%$ & \\
\hline Operational & & & $12,26 \%$ & \\
\hline Legal & & & $10,12 \%$ & \\
\hline Organizational & & & $9,48 \%$ & $9,87 \%$ \\
\hline Financial analysis & & & & $16,91 \%$ \\
\hline Financial plan & & & & $14,94 \%$ \\
\hline Executive summary & & & & $14,09 \%$ \\
\hline Project evaluation & & & & $12,73 \%$ \\
\hline Marketing & & & & $11,99 \%$ \\
\hline Entrepreneurs & & & & $11,68 \%$ \\
\hline Social impact & & & & $7,79 \%$ \\
\hline Total & $100 \%$ & $100 \%$ & $100 \%$ & $100 \%$ \\
\hline
\end{tabular}

In Table IV, in which all identified stages of the evaluation process are included (the first and the second are subsumed under only one stage), we emphasize the decision criteria that are used in each stage, presenting the results concerning the weighting of the different dimensions and criteria used in the evaluation process, according to the specific stage of development. The table summarizes the main results of this study, supporting our argument for the existence of a differential approach in terms of the tools, methodologies and decision criteria that are determinant in each stage. The data was obtained in the following way: respondents were asked to weight, in a scale that ranged from 0 to 1000 , the relative importance of each dimension, in each stage of the evaluation process. Responses to all dimensions were required, and the sum of the weights equalled, necessarily, 1000.

On the screening and idea evaluation stages, the main dimension is the market, followed by the technology and by a subjectivity factor. On the feasibility stage, it is the economic/financial dimension, and on the opportunity stage, the main dimension is the financial analysis. 
We realize that, not only are the tools and methodologies different, so is the nature of the criteria that underlies the use of those tools. In the early stages, subjectivity and qualitative approaches dominate the decision process, whereas structured and quantitative approaches are gradually superimposed or determine later stages. This is also true in the last stages, which we now present along with the ones that have already been discussed.

The main point here is that the evaluation process is a complex one that involves several stages, whose characteristics imply the adoption of different decision criteria supported by different tools and methodologies. In the first stages of the process, the stages that deal with idea generation and screening, qualitative and subjective criteria dominate the process. This is explained by the fact that there are not definite or consolidated concepts that can be conducive to qualitative analysis or to structured processes of evaluation, generally based on a quantitative approach. There is not yet a "dominant design", to make an analogy with the Abernathy/Utterback model [21], or a well defined concept, and as such there is no sure way to collect data or to rely on specific patterns of data. The technology that is being evaluated, is presumably of a new vintage, or it possesses characteristics that may not be totally familiar to the evaluator, so there may not be recorded or familiar references on which to rely a sound assessment. Of course, this may vary with the incremental or radical nature of the technology. Qualitative assessments, experience and intuition become relevant factors on these stages. In later stages, as the product concept is consolidated, and the requisites for data collection become much more established, quantitative assessments take over, eventually dominating the later stages, whereby uncertainty is reduced and information retrieval is maximized.

\section{CONCLUSION}

One of the main results of this research was the realization that the criteria, tools and methodologies that are adopted by firms are not uniform throughout the process of evaluation and adoption of the technologies. It depends on the stage of the process. Accordingly, we propose a division of the process in specified stages and we identify which criteria, tools and methodologies firms' values most at each one.

The identification of which criteria, and consequently, which tools and techniques are to be used in each stage of the process has important implications on the redefinition of current practices of technology evaluation, since the models presented in the literature do not refer explicitly to the differential application of criteria, tools and techniques depending on the time of the evaluation process. Current practices may benefit from this perspective, in the sense that specific criteria, and adequate tools and technique, are much more easily identified and adequately applied to the respective stage of the evaluation process. Practices that may tend to apply criteria that is not adequate at a certain stage (for instance, financial criteria at an early stage) and that lead to errors and decisions that are not properly sustained, will be avoided.

Further research on this issue will imply a proposal of a scoring model to accompany the division of specific process steps, identifying and considering the criteria for analysis of the potential of ideas appropriate to each stage. Within this proposal, the main distinguishing feature is the introduction of a variable on subjectivity in the analysis of innovative ideas, which, according to the results obtained in this research, is a methodology (including experience) often used in the selection of business opportunities makers in a context of uncertainty, especially in the early stages of development.

\section{REFERENCES}

[1] T. U. Daim and D. F. Kocaoglu, "How do engineering managers evaluate technologies for acquisition? A review of the electronics industry", Engineering Management Journal, vol. 20, no.3, pp $44-52$, Sep. 2008.

[2] A. Hidalgo and J. Albors, "Innovation management techniques and tools: a review from theory and practice", $R \& D$ Management, vol. 38, no. 2, pp 113-127, Mar. 2008.

[3] R.G. Cooper, S. J. Edgett and E. J. Kleinschmidt, "New problems new solutions: making portfolio management more efficient", Research Technology Management, vol. 43, no. 2, pp. 18-33, Mar. 2000.

[4] J. A. P. Salas, "Best practices for industry-university research collaboration", Master Dissertation, Massachusetts Institute of Technology, Cambridge, 2009.

[5] Y.-T. Wang, "Information technology investment decisions and evaluation in large Australian companies", Doctoral Dissertation. Griffith University, 2006.

[6] D. R. Jolly, "Development of a two-dimensional scale for evaluating technologies in high-tech companies: An empirical examination", Journal of Engineering and Technology Management, vol. 29, no. 2, pp. 307-329, Apr.-Jun. 2012.

[7] M. A. Schilling and C. W. L. Hill, "Managing the new product development process: Strategic imperatives", The Academy of Management Executive, vol. 12, no.3, pp. 6781, Aug. 1998.

[8] C. Floyd, Managing technology for corporate success. Hampshire: Gower Publishing, 1998.

[9] K. Milis, S. Snoeck and R. Haesen, "Evaluation of the applicability of investment appraisal techniques for assessing the business value of IS services", FBE Research Report, KBI_0910, pp. 1-9. K.U. Leuven, BE, 2009. (Retrieved from: https://lirias.kuleuven.be /handle/123456789/247210).

[10] A. S. Sohal, R. Schroder, E. O. Uliana and W. Maguire, "Adoption of AMT by South African manufacturers", Integrated Manufacturing Systems, vol. 12,no.1, pp. 15 34, 1998.

[11] B. C. Twiss, Business for engineers. London: Peter Peregrinus Ltd., 1991.

[12] L. Yan, Z. Hong and H. Lucheng, "Review on methods of new technology valuation", in Proceedings of 2010 International Conference on E-Business and E- 
Government, ICEE, Guangzhou, China, pp 1932-1935, 2010.

[13] M. Dissel, C. Farrukh, D. Probert, and R. Phaal, “ Evaluating early stage technology valuation methods: what is available and what really matters", in Proceedings from 2005 IEEE International Engineering Management Conference, St John's, Newfoundland, Canada, vol. 2, pp 302-306, 2005.

[14] A. Damodaran, The dark side of valuation: valuing old tech, new tech, and new economy companies. London: Financial Times Prentice Hall, 2001.

[15] S. Ordoobadi, "Inclusion of risk in evaluation of advanced technologies", International Journal of Advanced Manufacturing Technology, vol. 54, no.1-4, pp. 413-420, 2011.

[16] V. Chiesa and F. Frattini, "Evaluation and performance measurement of research and development: techniques and perspectives for multi-level analysis", $R \& D$ Management, vol. 40, no.5, pp. 513-514, 2010.

[17] S. Ordoobadi, "Development of a tool for managing technological innovations in small manufacturing companies", in Proceedings of the 7th Asia Pacific Industrial Engineering and Management Systems Conference, Bangkok, Thailand, 2006.

[18] P. F. Drucker, The practice of management. New York: Harper Collins, Reissued ed. 1993.

[19] F. E. See and R. T. Clemen, "Psychological and organizational factors influencing decision process innovation: The role of perceived threat to managerial power", Working paper, Duke University, Durham, NC, 2005.

[20] GPEARI, IPCTN10: resultados provisórios. Lisboa: GPEARI-Ministério da Ciência, Tecnologia e Ensino Superior, 2011.

[21] W. J. Abernathy and J. M. Utterback, "Patterns of industrial innovation", Technology Review, vol. 80, no.7, pp. 40-47, 1978. 